\title{
Development and characterisation of Vitex negundo Linn. noodles
}

\author{
Tan, L.S., Leila, M. and *Rabeta, M.S. \\ Food Technology Division, School of Industrial Technology, Universiti Sains Malaysia, 11800, Minden, \\ Pulau Pinang, Malaysia
}

\begin{abstract}
Article history:
Received: 14 September 2017

Received in revised form: 19

September 2017

Accepted: 22 September 2017

Available Online: 2 October

2017
\end{abstract}

Keywords:

Proximate analysis,

Total phenolic content,

Microbial analysis,

Sensory test,

Texture analysis,

Noodle

\begin{abstract}
Formulation $2(1 \mathrm{~g} \mathrm{w} / \mathrm{w})$ was the most favourable and was chosen for further analyses to compare its composition with that of a control $(0 \mathrm{~g} \mathrm{w} / \mathrm{w})$. Total phenolic content (TPC) of the fresh noodles remained higher than that of the control even after cooking. However, after cooking, the carbohydrate and protein contents showed significant increases. The results showed that the lemuni-supplemented noodles have a longer shelf life compared to the control. The colour parameters $\mathrm{L}^{*}$ and $\mathrm{a}^{*}$ also showed significant differences as the lightness decreased, and the redness increased after the substitution. The $\mathrm{L}^{*}, \mathrm{a}^{*}$ and $\mathrm{b}^{*}$ values decreased significantly after the noodles of both formulations were cooked. The tensile strength, adhesiveness, and hardness of the lemuni noodles were significantly higher than those of the control. Thus, the Vitex negundo Linn. leaf has the potential to increase the health benefits of food products.
\end{abstract}

DOI:

https://doi.org/10.26656/fr.2017.2(1).228

\section{Introduction}

A functional food is any food that has been demonstrated to provide benefit to one or more target functions in the body to improve health, reduce the risk of disease, or provide nutrients (Gibson and Williams, 2000). Functional foods are divided into particular categories that offer different benefits to human health. These categories include fortification with vitamins and minerals, reduction of cholesterol, and added dietary fibre, antioxidants, phytochemicals, herbals and botanical effects, as well as probiotics, prebiotics, and synbiotics (Gibson and Williams, 2000).

Lemuni, scientifically known as Vitex negundo Linn., is a type of medicinal plant that is widely found in Asia and other parts of the world. Vitex negundo Linn. is consumed as an ingredient in food preparation in the northern region and east coast of Peninsular Malaysia. Apart from rice and bread, noodles are another staple in Asia. Noodles can be prepared using different formulations. Wheat, rice, buckwheat, and starches from potatoes, sweet potatoes and pulses can be used to make noodles (Fu, 2008). Other ingredients that are usually added to noodles are water, salt, egg, and alkaline solutions such as those containing sodium bicarbonate
(Kim et al., 2006; Fu, 2008; Hou et al., 2010). Noodles provide ample amounts of essential nutrients such as carbohydrates and protein. There are a few types of noodles such as egg noodles, instant noodles, alkaline noodles, and soba. Since noodles are one of the most popular foods in Asia, extensive efforts have been made in developing additional flavours and aromas to add to the variety of noodle choices in the marketplace.

The rationale of this study is to fully utilise a traditional medicinal plant known as Vitex negundo Linn. that is rich in antioxidants. This study was inspired by a previous study that encouraged utilising this plant for commercial purposes (Brindha et al., 2012). In this study, lemuni leaf powder is substituted for some of the wheat flour in common noodles. The substitution of lemuni leaf powder in noodle production is a good idea to develop a functional food that can provide health benefits. This study is conducted to determine whether substitution with lemuni will increase the total phenolic content of the noodles as well as their antimicrobial properties. A study of the shelf life was also conducted to observe the biological changes of the noodles. 


\section{Materials and methods}

\subsection{Raw materials}

Leaves of Vitex negundo L. were harvested from Kuala Kurau, Perak in middle of October 2013. The leaves were identified by Mr. Adnan Jaafar. The voucher specimen (USM Herbarium 11461) was deposited in the herbarium of School of Biological Sciences, Universiti Sains Malaysia. The basic ingredients that were used in noodles making include wheat flour manufactured by Prestasi Flour Mill (M) Sdn Bhd (317371-A), salt and distilled water.

\subsection{Chemicals}

Folin-Ciocalteau reagent (Sigma-Aldrich), Gallic acid (Sigma-Aldrich), methanol, 7\% sodium carbonate (QRëC®), petroleum ether (QRëC®), $0.1 \quad \mathrm{M}$ hydrochloric acid (QRëC () ), copper sulphate (catalyst) (Gerhardt), 5\% and concentrated sulphuric acid (Fisher Scientific), 4\% boric acid (Hopkins and Williams), methyl red (Merck), 1\% hydrochloric acid (QRëC®), $25 \%, \quad 35 \%$ and $40 \%$ sodium hydroxide (QRëC $($ ) ), phenolphthalein indicator (Merck), spirit methyl (Merck), plate count agar powder (Merck Millipore), potato dextrose agar powder (Merck Millipore), and buffered peptone water (Merck Millipore).

\subsection{Preparation of Lemuni leaf powder}

The leaves were plucked from the stems, washed and air-dried, and they were then freeze-dried for three days at $-50^{\circ} \mathrm{C}$. The freeze-dried leaves were ground and milled by into very small particles generally less than $250 \mu \mathrm{m}$ using a blender and stored at $-20^{\circ} \mathrm{C}$ until use.

\subsection{Preparation and formula of noodles}

All of the ingredients for each formulation were mixed homogeneously using a Kitchen Aid Mixer (using a speed of 1 for 15 minutes), and the dough formed was then left to rest for 30 minutes before sheeting and slitting using a noodle machine. Finally, the noodle strands were cooked in boiling water for five minutes and immersed in cold water for one minute.

\subsection{Sensory evaluation}

Sensory evaluation was carried out by thirty students selected randomly from the School of Industrial Technology. During the evaluation period, all of the formulations of the noodles were assessed. The sensory attributes that were tested were the aroma, colour, taste, texture and overall acceptability. A 7-point hedonic scale was used in this sensory evaluation, where 1 represents 'dislike very much' and 7 represents 'like very much'. A sensory laboratory with partitioned booths was used to conduct the sensory evaluation.

\subsection{Extraction of sample}

Sample extraction was carried out to measure the total phenolic content of lemuni noodles according to the protocol described by $\mathrm{Yu}$ et al. (2013). The extraction steps were slightly modified to make them suitable for the products. Approximately $7 \mathrm{~g}$ of raw and cooked noodles were homogenised using an IKA ${ }^{\circledR}$ T25 digital Ultra-Turrax homogeniser at $11.0 \times 1000 \mathrm{rpm} / \mathrm{min}$ for 3 minutes in $50 \mathrm{ml}$ of methanol/ water $(80 / 20, \mathrm{v} / \mathrm{v})$. The samples were then shaken in a Memmert water bath shaker for an hour at the speed of 4 , followed by centrifugation in a Kubota 5100 at 3,300 rpm/ min for 10 minutes. The supernatant was separated, and the residue was extracted twice more using the same steps. All of the supernatants were collected and vacuum-evaporated by EYELA OSB-2100 and N-1200B rotary evaporators at $45^{\circ} \mathrm{C}$ until dry, and the extracts were redissolved in methanol to a volume of $10 \mathrm{ml}$ and stored in the dark at $4^{\circ} \mathrm{C}$ until use.

\subsection{Determination of total phenolic content}

The total phenolic content of the noodles was evaluated using the Folin-Ciocalteu assay. Approximately $125 \mu \mathrm{L}$ of the standard or diluted extracts was mixed with $500 \mu \mathrm{L}$ of distilled water and $125 \mu \mathrm{L}$ of the Folin-Ciocalteu reagent. The mixture was left to stand at room temperature $\left(28^{\circ} \mathrm{C}\right)$ for 6 minutes, and approximately $1.25 \mathrm{~mL}$ of $7 \%$ sodium carbonate and 1 $\mathrm{mL}$ of distilled water were then added. The mixture was incubated in the dark for 90 minutes and measured using a UV-160A UV-Visible Recording Spectrophotometer (Shimadzu) at $760 \mathrm{~nm}$. In this evaluation, gallic acid was used as a standard, and the result was expressed as mg of gallic acid equivalents (GAE/ 100 g d.w.).

\subsection{Proximate analysis}

The proximate analysis of lemuni noodles, which included moisture content, ash, crude protein, fat, and crude fiber, was determined according to the methods set forth by the Association of Analytical Chemists (AOAC, 2000). The percentage of carbohydrate content was determined by the following formula:

$\%$ Carbohydrate $=100-(\%$ ash $+\%$ fat $+\%$ protein $+\%$ fiber content)

\subsection{Determination of shelf life of noodles}

The shelf life of the noodles was observed for five 
consecutive weeks, from week 0 to week 4 . Two analyses, microbial analysis and measurement of $\mathrm{pH}$, were carried out on the noodles which were kept in a closed container, refrigerated at $4^{\circ} \mathrm{C}$.

\subsection{Microbial analysis}

The in vitro antimicrobial activity of the lemuni noodles was screened in duplicate using bacteria, yeast, and mould. The total plate count was determined using Plate Count Agar (PCA) followed by Potato Dextrose Agar (PDA) to determine the yeast and mould growth. The samples were analysed weekly for four weeks. Approximately $10 \mathrm{~g}$ of sample was homogenised in a stomacher bag of $90 \mathrm{ml}$ of $0.1 \%$ buffered peptone water using a stomacher machine for 2 minutes. Serial dilutions of the samples were prepared up to $10^{-5}$, and the pour plate method was applied by pipetting $1 \mathrm{ml}$ of sample into an agar plate and pouring approximately 15 $\mathrm{ml}$ of agar into the same agar plate. The samples in PCA were incubated at $37^{\circ} \mathrm{C}$ for 24 hours, and the samples in PDA were incubated at $25^{\circ} \mathrm{C}$ for 72 hours. After the incubation period, the number of colonies that grew was determined.

\section{$2.11 \mathrm{pH}$ measurement}

The $\mathrm{pH}$ of the samples was determined in triplicate using a Mettler Toledo $\mathrm{pH}$ meter. A total of $10 \mathrm{~g}$ of sample was homogenised in $90 \mathrm{~mL}$ of distilled water for two minutes in a stomacher bag using a stomacher machine and then analysed using the $\mathrm{pH}$ meter.

\subsection{Colour measurement}

The colour of the noodles was measured using a Minolta Spectrophotometer CM-3500d colorimeter. The colorimeter was calibrated using an empty dish followed by a white mask. The values of $L, a^{*}, b^{*}$ were determined in triplicate and recorded.

\subsection{Texture analysis}

The textural properties of the cooked noodles were measured using a TA-XTplus Texture Analyzer. The tensile strength of a strand of noodles was tested using an A/SPR probe at a pre-test speed of $3.0 \mathrm{~mm} / \mathrm{s}$, a test speed of $3.0 \mathrm{~mm} / \mathrm{s}$, and a post-test speed of $5.0 \mathrm{~mm} / \mathrm{s}$. A strand of noodle was pulled to a distance of $100 \mathrm{~mm}$ using a load cell of $5 \mathrm{~kg}$

A texture profile analysis (TPA) was performed on the noodles using a cylindrical probe with a diameter of $36 \mathrm{~mm}$ and a load cell of $5 \mathrm{~kg}$. The measurement was set at $2.0 \mathrm{~mm} / \mathrm{s}$ for the pre-test speed and $0.8 \mathrm{~mm} / \mathrm{s}$ for the test speed and the post-test speed. Then, 1 noodle strand was placed parallel on the middle of the compression surface to test the springiness, hardness, resilience, cohesiveness, and adhesiveness of the noodles.

\subsection{Statistical analysis}

All analyses were performed in triplicate, and the data were analysed using SPSS software (16 ${ }^{\text {th }}$ Edition). The data were analysed using the one-way analysis of variance (ANOVA) and Duncan's multiple tests to determine any significant differences among the samples. Differences between samples were considered significant when $\mathrm{p}<0.05$. The values were expressed in the form of means \pm standard deviations.

\section{Results and discussion}

\subsection{Sensory evaluation of noodles}

Table 1 shows the acceptability of the noodles to the thirty panellists based on the five quality attributes examined in the sensory evaluation. There were significant differences $(\mathrm{p}<0.05)$ between all formulations with respect to the quality attributes. The control in this study was the most preferred formulation, followed by the formulation 2 noodle among the four formulations evaluated. There were no significant differences $(\mathrm{p}>0.05)$ among attributes compared to the control of the study except for the colour perception. Therefore, the panellists' preference against the formulation 2 noodle is similar to that of the control of this study. Additionally, formulation 3 noodle has two quality attributes that showed significant differences $(\mathrm{p}<0.05)$ from the control,

Table 1. Quality attributes examined during sensory evaluation of lemuni noodles with different formulations

\begin{tabular}{cccccc}
\hline Formulation & Aroma & Colour & Taste & Texture & $\begin{array}{c}\text { Overall } \\
\text { Acceptability }\end{array}$ \\
\hline 1 & $4.47 \pm 1.20^{\mathrm{a}}$ & $5.37 \pm 1.13^{\mathrm{a}}$ & $4.40 \pm 1.40^{\mathrm{a}}$ & $4.87 \pm 1.36^{\mathrm{a}}$ & $4.73 \pm 1.39^{\mathrm{a}}$ \\
2 & $4.30 \pm 1.15^{\mathrm{ab}}$ & $3.97 \pm 1.45^{\mathrm{b}}$ & $3.93 \pm 1.34^{\mathrm{ab}}$ & $4.48 \pm 1.30^{\mathrm{ab}}$ & $4.37 \pm 1.19^{\mathrm{ab}}$ \\
3 & $3.90 \pm 1.09^{\mathrm{ab}}$ & $3.73 \pm 1.11^{\mathrm{b}}$ & $3.90 \pm 1.16^{\mathrm{ab}}$ & $4.27 \pm 1.23^{\mathrm{ab}}$ & $3.90 \pm 0.99^{\mathrm{bc}}$ \\
4 & $3.77 \pm 1.48^{\mathrm{b}}$ & $3.40 \pm 1.61^{\mathrm{b}}$ & $3.23 \pm 1.30^{\mathrm{b}}$ & $4.00 \pm 1.46^{\mathrm{b}}$ & $3.47 \pm 1.28^{\mathrm{c}}$ \\
\hline
\end{tabular}

Mean \pm standard deviation $(n=30)$. Mean value within a column with the different alphabet are significantly different $(\mathrm{p}<0.05)$, as determined by Duncan's multiple test. 
namely, the colour and overall acceptability. The overall acceptability of the formulation 3 and 4 noodles had significant differences $(p<0.05)$ from the control. Thus, the sensory evaluation results led to formulation 2 being selected as a representative formulation of noodles substituted with lemuni leaf for further analyses against the control.

Some panellists commented that the noodles with the substitution with lemuni leaf had a good and acceptable aroma, but most panellists suggested improving the aroma. The acceptability of the noodle aroma was very subjective and depended very much on each individual's preference. From Table 1, there was a significant difference $(p<0.05)$ between formulations 1 and 2 for the colour of the noodles. A few panellists commented that the colour of the noodles with higher additions of lemuni leaf powder was too dark and unpleasant. The variations in the noodle colour were also high among the four formulations. The colour intensity increased as the amount of lemuni leaf powder increased. However, the only significant differences $(p<0.05)$ observed were between formulation 1 and the other three formulations, as formulations 2, 3 and 4 did not show any significant differences $(p>0.05)$ among themselves.

Lemuni is a type of herb that is traditionally used and exhibits an herbal aroma and taste (Vishal, 2005; Vishwanathan and Basavaraju, 2010). Some of the panellists were able to perceive a bitter taste in the noodles with lemuni leaf powder. Vishal (2005) reported that the leaf of this plant is bitter and aromatic. The intensity of the bitterness depends on the amount of lemuni leaf powder added to the noodles. Increasing the amount of lemuni leaf powder increases the aroma, taste, and bitterness of the noodles. Panellists that like an herbal taste would like the taste of the noodles with lemuni leaf powder added, and vice versa. Significant differences $(p<0.05)$ in the taste and texture of the formulations were shown between formulations 1 and 4 .

Most panellists preferred the formulation with the smallest addition of lemuni leaf powder. This preference was highly affected by the aromas, colours and tastes of the noodles of the different formulations.

\subsection{Total phenolic content (TPC) of noodles}

There are several types of solvents that can be used for extraction, such as methanol, water, ethanol, acetone, propanol, ethyl acetate and dimethylformamide. Rabeta and An Nabil (2013) showed that the methanol extraction of Vitex negundo Linn. was more effective than an aqueous extraction in terms of a number of phenolic compounds recovered. Dai and Mumper (2010) reported that methanol was found to be an effective extraction solvent for lower molecular weight polyphenols, while aqueous acetone was preferable for higher molecular weight flavanols.

In this study, the phenolic compounds in the noodles were extracted according to $\mathrm{Yu}$ et al. (2013), using a mixture of methanol and water at a ratio of $4: 1$ as the extraction solvent. The total phenolic content was quantified based on a linear equation obtained from a standard calibration curve using gallic acid. The standard calibration curve determined is $y=0.0098 x+0.101\left(r^{2}=\right.$ $0.9965)$, where $y$ is the absorbance at $760 \mathrm{~nm}$, and $\mathrm{x}$ is the concentration of gallic acid. TPC values are expressed as gallic acid equivalents (mg GAE/ $100 \mathrm{~g}$ d.w).

As shown in Table 2, the TPC of formulation 1 of fresh noodles $(\mathrm{FN})$ was significantly different $(\mathrm{p}<0.05)$ from that of formulation 2 . The substitution with lemuni leaf powder tremendously increased the amount of TPC, even though only $1 \mathrm{~g}(\mathrm{w} / \mathrm{w})$ of wheat flour was substituted in formulation 2. Prior to cooking, the TPC of the formulation 1 cooked noodles $(\mathrm{CN})$ was $75.41 \pm 2.46$ mg GAE/ $100 \mathrm{~g}$ d.w., whereas that for the formulation 2 noodles was $133.47 \pm 2.84 \mathrm{mg} \mathrm{GAE} / 100 \mathrm{~g}$ d.w. After cooking in boiling water for five minutes, the TPCs of the two formulations were significantly different $(p<0.05)$, with formulation 2 having a lower concentration than formulation 1 . The concentration of the cooked formulation 2 noodles was $114.08 \pm 3.57 \mathrm{mg}$ GAE/ $100 \mathrm{~g}$ d.w., compared to $48.88 \pm 2.22 \mathrm{mg} \mathrm{GAE} / 100$ $\mathrm{g}$ d.w. for the formulation 1 noodles.

Rabeta and An Nabil (2013) reported the presence of TPC in the leaves of Vitex negundo Linn. The substitution of lemuni leaf powder in the noodles was the main contributor of the TPC in the noodles. However, the antioxidant activity was not determined in this study. Thus, a further study is needed to determine the antioxidant activity of the noodles.

\subsection{Proximate analysis of noodles}

The proximate composition loss of the both formulations 1 and 2 noodles after cooking was done. Noodles were cooked for five minutes in boiling water. Proximate analysis such as moisture, ash, crude protein, crude fat and crude fibre contents were carried out. The carbohydrate content was calculated by using $100 \%$ deducting the other contents prior stated (100\% moisture content - ash - crude protein - crude fat crude fibre) 
Table 2. Proximate content and TPC of the fresh and cooked noodles of both formulas

\begin{tabular}{cccccccc}
\hline \multirow{2}{*}{ Formulation } & \multicolumn{5}{c}{ Proximate Content (\%) } & \multirow{2}{*}{ TPC } \\
\cline { 2 - 7 } & & Carbohydrate & Moisture & Ash & Crude Protein & Crude Fat & \\
\hline \multirow{2}{*}{ FN } & 1 & $51.30 \pm 1.97^{\mathrm{a}}$ & $34.94 \pm 1.61^{\mathrm{d}}$ & $1.63 \pm 0.02^{\mathrm{a}}$ & $8.73 \pm 0.18^{\mathrm{a}}$ & $3.40 \pm 0.60^{\mathrm{a}}$ & $75.41 \pm 2.46^{\mathrm{c}}$ \\
& 2 & $49.80 \pm 0.28^{\mathrm{a}}$ & $37.34 \pm 0.08^{\mathrm{c}}$ & $1.70 \pm 0.07^{\mathrm{a}}$ & $8.83 \pm 0.16^{\mathrm{a}}$ & $2.33 \pm 0.52^{\mathrm{ab}}$ & $133.47 \pm 2.84^{\mathrm{a}}$ \\
\multirow{2}{*}{$\mathrm{CN}$} & 1 & $22.48 \pm 0.42^{\mathrm{c}}$ & $70.41 \pm 0.48^{\mathrm{a}}$ & $0.32 \pm 0.11^{\mathrm{b}}$ & $4.19 \pm 0.19^{\mathrm{c}}$ & $2.60 \pm 0.77^{\mathrm{a}}$ & $48.88 \pm 2.22^{\mathrm{d}}$ \\
& 2 & $29.89 \pm 0.61^{\mathrm{b}}$ & $62.71 \pm 0.74^{\mathrm{b}}$ & $0.42 \pm 0.16^{\mathrm{b}}$ & $5.54 \pm 0.16^{\mathrm{b}}$ & $1.44 \pm 0.13^{\mathrm{b}}$ & $114.08 \pm 3.57^{\mathrm{b}}$ \\
\hline
\end{tabular}

Mean \pm standard deviation $(n=3)$. Mean value within a column with the different alphabet are significantly different $(\mathrm{p}<0.05)$, as determined by Duncan's multiple test

Table 3 revealed that the moisture content of the fresh noodles increased after the substitution of lemuni leaves powder. The moisture content of formulation 2 fresh noodles increases by $2.40 \%$ compared to formulation 1 noodle where there was a significant difference at $\mathrm{p}<0.05$. The moisture content of both formulations increased when cooked. In the comparison of both formulations, formulation 1 noodle has less moisture content prior to cook. However, after cooking in boiling water it has higher moisture content than formulation 2 noodle. The water absorption ability by formulation 1 was higher than formulation 2, similarly, in Li et al. (2012), the water absorption of noodles decreases as the substitution of superfine green tea powder increases up to $2 \mathrm{~g} / 100 \mathrm{~g}(\mathrm{w} / \mathrm{w})$.

Table 3. Microbial quantities on the total plate count and yeast and mould count of the fresh noodles

\begin{tabular}{ccccc}
\hline \multirow{2}{*}{ Week } & \multicolumn{2}{c}{ Formulation 1 } & \multicolumn{2}{c}{ Formulation 2 } \\
\cline { 2 - 5 } & TPC, & YMC, & TPC, & YMC, \\
& CFU/g & CFU/g & CFU/g & CFU/g \\
\hline 0 & $<25$ & $<25$ & $<25$ & $<25$ \\
& $4.55 \mathrm{x}$ & $<25$ & $<25$ & $<25$ \\
& $10^{2}$ & $2.18 \mathrm{x}$ & $<25$ & $<25$ \\
2 & $3.48 \mathrm{x}$ & $10^{4}$ & & \\
& $10^{3}$ & $1.35 \mathrm{x}$ & $4.15 \mathrm{x}$ & $9.98 \mathrm{x}$ \\
3 & $5.40 \mathrm{x}$ & $10^{7}$ & $10^{5}$ & $10^{3}$ \\
& $10^{7}$ & $1.12 \mathrm{x}$ & $\mathrm{TNTC}$ & $5.18 \mathrm{x}$ \\
4 & $\mathrm{TNTC}$ & $10^{7}$ & & $10^{4}$ \\
\hline
\end{tabular}

TPC - total plate count, YMC - yeast and mould count, and TNTC - too numerous to count

Table 3 proposed that the initial ash contents for both formulations did not show any significant difference $(\mathrm{p}>$ 0.05), but when cooked, it is observed that both formulations have reduced their ash content. Additionally, formulation $2(0.42 \pm 0.16)$ noodle has retained a higher amount of ash compared to formulation $1(0.32 \pm 0.11)$ noodles even though no significant difference $(\mathrm{p}>0.05)$. Ritthiruangdej et al. (2011) mentioned that the ash content of noodles depends on the quality of the flour which corresponds to the higher mineral content. Kumar et al. (2013) found that Vitex negundo Linn. leaves contain minerals such as chromium, potassium, iron, copper, zinc, and calcium. These mineral components add to the ash content in the formulation 2 noodle. However, the substitution of lemuni leaves powder in formulation 2 was too little to show a significant difference compared to its initial ash content.

The initial crude protein contents for both formulations did not differ much as there was no significant difference $(\mathrm{p}>0.05)$ as shown in Table 3 . Kumar et al. (2013) showed that Vitex negundo Linn. leaves consist a little amount of protein which contributes to the percentage increment of crude protein in formulation 2 noodle. However, after cooking, both protein contents decreased. The cooking loss of formulation 1 was much higher compared to formulation 2 , which was the former dropped by $4.54 \%$ and the latter dropped by only $3.39 \%$. The crude protein of formulation $1 \quad(4.19 \pm 0.19)$ cooked noodle was significantly different $(\mathrm{p}<0.05)$ from formulation 2 (5.54 \pm 0.16$)$ cooked noodle. The lesser amount of crude protein loss in formulation 2 noodles after cooking may due to the substitution of lemuni leaves powder that helps in strengthening the gluten matrix structure, hence, reduced protein loss.

The crude fat content of the noodles for both formulations was relatively low and showed no significant difference $(p>0.05)$ in fresh noodles for both formulations. The initial crude fat content in the noodles shown in Table 3 was very little and formulation 2 of fresh noodle has lower fat content compared to formulation 1 of fresh noodle. Those amounts of crude fats dropped after cooking with a significant difference $(p<0.05)$ for both formulations. The crude fat content of formulation $2(1.44 \pm 0.13 \%)$ noodles was significantly lower than that of formulation $1(2.60 \pm 0.77 \%)$ noodles $(\mathrm{p}<0.05)$. Kumar et al. (2013) showed that Vitex negundo Linn. comprised of trace amount of fat, however, it did not contribute to the crude fat content of the noodle. Fresh noodles were sprinkled with wheat flour to reduce stickiness rather than spreading the oil. 
Both formulations showed no trace of crude fibre found during the analysis. Therefore, it was assumed that the substitution of lemuni leaves powder does not increase the content of crude fibre.

The initial carbohydrate content of the noodles tabulated in Table 3 was relatively quite high and showed no significant difference $(p>0.05)$ in comparison for both formulations. Formulation 1 noodles dropped by $56 \%$ while formulation 2 noodles dropped by only $40 \%$ after cooking. The substitution of lemuni leaves powder may have affected the carbohydrate content of the cooked noodles, where it showed a significant difference $(\mathrm{p}<0.05)$ of the cooked noodles for both formulations. The lemuni leaves powder may have helped in holding the carbohydrate loss during cooking.

\subsection{Microbial analysis of noodles}

The total plate count (TPC) and yeast and mould count (YMC) were the microbial analyses that were carried out to determine the shelf life of the fresh noodles. The results of the microbial enumeration were tabulated in Table 4. At week 0 of the analysis, there was less than $25 \mathrm{CFU} / \mathrm{g}$ of bacterial and yeast and mould growth in the freshly made noodles for both formulations. Ghaffar et al. (2009) found that the maximum level of freshly made noodles should not be more than $10^{6} \mathrm{CFU} / \mathrm{g}$.

Table 4. Colour measurements of the noodles

\begin{tabular}{ccccc}
\hline \multirow{2}{*}{ Formulation } & \multicolumn{3}{c}{ Colour Parameter } \\
\cline { 2 - 5 } & & $\mathrm{L}^{*}$ & $\mathrm{a}^{*}$ & $\mathrm{~b}^{*}$ \\
\hline \multirow{2}{*}{$\mathrm{FN}$} & 1 & $64.03 \pm 1.48^{\mathrm{a}}$ & $-1.19 \pm 0.13^{\mathrm{b}}$ & $13.85 \pm 0.51^{\mathrm{a}}$ \\
& 2 & $39.58 \pm 0.45^{\mathrm{c}}$ & $0.47 \pm 0.17^{\mathrm{a}}$ & $13.51 \pm 0.92^{\mathrm{a}}$ \\
& 1 & $50.07 \pm 0.92^{\mathrm{b}}$ & $-1.63 \pm 0.05^{\mathrm{c}}$ & $-0.30 \pm 0.03^{\mathrm{c}}$ \\
$\mathrm{CN}$ & 2 & $35.74 \pm 0.13^{\mathrm{d}}$ & $-1.25 \pm 0.13^{\mathrm{b}}$ & $5.18 \pm 0.33^{\mathrm{b}}$ \\
\hline
\end{tabular}

Mean \pm standard deviation $(n=3)$. Mean value within a column with the different alphabet are significantly different $(\mathrm{p}<0.05)$, as determined by Duncan's multiple test

On week 1, the TPC plate for formulation 1 increased to $4.55 \times 10^{2} \mathrm{CFU} / \mathrm{g}$, while the $\mathrm{YMC}$ remained below $25 \mathrm{CFU} / \mathrm{g}$. A gradual increase in the microbial growth for the formulation 1 noodles was observed beginning at week 2 . The microbial growth in the formulation 1 noodles rapidly increased in weeks 2 and 3 , while the TPC bacterial quantity increased to $3.48 \mathrm{x}$ $10^{3} \mathrm{CFU} / \mathrm{g}$ and $5.40 \times 10^{7} \mathrm{CFU} / \mathrm{g}$, respectively, and the YMC quantity increased to $2.18 \times 10^{4} \mathrm{CFU} / \mathrm{g}$ and $1.35 \mathrm{x}$ $10^{7} \mathrm{CFU} / \mathrm{g}$, respectively. In the fourth week, the number of colonies in the TPC became too numerous to count, but the YMC quantity remained the same as in week 3 .
Additionally, in formulation 2, distinct microbial growth was only observed in the third week. The TPC quantity was $4.15 \times 10^{5}$ in week 3 and higher in the fourth week, where the number of colonies was too numerous to determine. Similarly, the YMC count in week 3 was $9.98 \times 10^{3} \mathrm{CFU} / \mathrm{g}$, and it increased to $5.18 \mathrm{x}$ $10^{4} \mathrm{CFU} / \mathrm{g}$ in week 4 . Thus, the formulation 1 noodle was impaired earlier compared to formulation 2, giving it a shorter shelf life. This condition fits the studies claimed that Vitex negundo Linn. has antimicrobial activity, as the noodle containing its substituted leaf powder had a longer shelf life compared to the control. Study done by Senatore et al. (2003) found the presence of cineole, myrcene, $\alpha$-terpineol as antibacterial activity in violet flower of Vitex agnus-castus

\section{$3.5 \mathrm{pH}$ measurement of noodles}

Figure 1 shows the decreasing trends from week 0 to week 4 for both formulations of noodles. There were no significant differences $(\mathrm{p}>0.05)$ in $\mathrm{pH}$ changes for the two formulations during week 0 and week 1 . Formulation 1 has a stable $\mathrm{pH}$ of 5.91 in weeks 0 and 1. However, its $\mathrm{pH}$ decreases tremendously to $\mathrm{pH} 5.77$ in week 2 , representing a significant difference $(p<0.05)$ in the $\mathrm{pH}$ changes. The formulation 1 noodle maintained its $\mathrm{pH}$ in week 3 and dropped again in week 4.

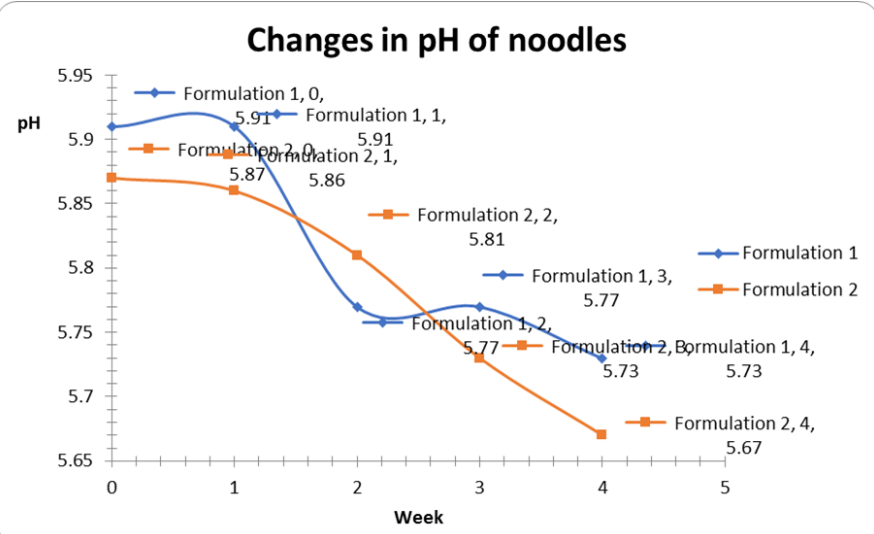

Figure 1. Changes in the $\mathrm{pH}$ of the noodles from week 0 to week 4

The $\mathrm{pH}$ for the formulation 2 noodle decreased gradually from week 0 to week 4 . Its initial $\mathrm{pH}$ was lower compared to that of formulation 1 , with a value of 5.87. Additionally, it decreased by 0.01 but showed no significant difference $(\mathrm{p}>0.05)$. However, the decreasing $\mathrm{pH}$ values in weeks 2,3 and 4 showed significant differences $(\mathrm{p}<0.05)$ in the $\mathrm{pH}$ changes.

The changes in the $\mathrm{pH}$ during the shelf life period might be due to the microbiological activities in the noodles. Noodles rich in nutritional components such as carbohydrates and proteins encourage the growth of microorganisms, which produce acid and reduce the $\mathrm{pH}$. 
Table 5. Texture profile analyses and tensile strength of the cooked noodles

\begin{tabular}{ccccccc}
\hline Formulation & Hardness & Adhesiveness & Springiness & Cohesiveness & Resilience & $\begin{array}{c}\text { Tensile Strength } \\
\left(\mathrm{N} / \mathrm{cm}^{2}\right)\end{array}$ \\
\hline 1 & $37.61 \pm 0.41$ & $-367.13 \pm 31.93$ & $0.91 \pm 0.01$ & $0.71 \pm 0.01$ & $0.43 \pm 0.02$ & $24.76 \pm 0.81$ \\
2 & $45.02 \pm 0.46$ & $-642.62 \pm 79.36$ & $0.91 \pm 0.01$ & $0.71 \pm 0.02$ & $0.43 \pm 0.03$ & $26.34 \pm 0.54$ \\
\hline
\end{tabular}

Mean \pm standard deviation $(\mathrm{n}=3)$.

Additionally, microorganisms favour and actively grow on food with a high moisture content and water activity (Ghaffar et al., 2009).

\subsection{Colour measurement of noodles}

The colour measurement was conducted on fresh and cooked noodles for both formulations. The values of $\mathrm{L}^{*}, \mathrm{a}^{*}$ and $\mathrm{b}^{*}$ measured are tabulated in Table 5. The $\mathrm{L}^{*}$, or the lightness, of the formulation 1 fresh noodles was the highest at a reading of $64.03 \pm 1.48$. As shown in Table 4.5 , there was a significant difference $(p<0.05)$ in the $L^{*}$ of the fresh and cooked noodles for both formulations. As the lemuni leaf powder was substituted by 1 gram, the lightness decreased by almost $40 \%$. After the formulation 1 noodle was cooked, the lightness decreased by $22 \%$, while that of the cooked formulation 2 noodles decreased by only $9.70 \%$.

There was a significant difference $(\mathrm{p}<0.05)$ in the substitution of lemuni leaf powder in the $a^{*}$ value compared to the control. The cooked noodles of formulation 1 showed a significant difference $(p<0.05)$ compared to the fresh noodles in its $a^{*}$ value, as did those of formulation 2. As for the $b^{*}$ values, the fresh noodles of the two formulations showed no significant difference $(p>0.05)$ and were yellowish in colour. Both formulations' $b^{*}$ values decreased upon cooking and showed a significant difference $(\mathrm{p}<0.05)$. In formulation 1 , the $b^{*}$ values dropped tremendously, moving slightly towards blueness, while the formulation 2 noodles' $\mathrm{b}^{*}$ values dropped but still maintained a slightly yellowish colour.

The original colour of the leaf powder is greenish, so it decreased the lightness of the noodles. This is shown in the $\mathrm{L}^{*}$ values in Table 5 . After the noodles were cooked, the colour of the noodles decreased tremendously as the components leached out during boiling.

\subsection{Tensile strength of noodles}

The tensile strength of the formulation 1 noodle was $24.76 \pm 0.81 \mathrm{~N} / \mathrm{cm}^{2}$, compared to $26.34 \pm 0.54 \mathrm{~N} / \mathrm{cm}^{2}$ for the formulation 2 noodle, with a significant difference at $\mathrm{p}<0.05$. Although Ritthiruangdej et al. (2011) claimed that removing wheat flour would weaken the noodle texture, the formulation 2 noodle actually has a slightly higher tensile strength compared to the formulation 1 noodle. The differences could be because the substitution of lemuni leaf powder into the noodles strengthens the gluten network of the noodle strands. Kong et al. (2012) described in their study that starches, proteins, fibre and other ingredients will affect the texture by either weakening or strengthening the hydrogen bonds within the noodle matrix network.

\subsection{Texture profile analysis (TPA) of noodles}

The addition of lemuni leaf powder increased the hardness and adhesiveness of the noodles, with both properties showing significant differences $(p<0.05)$ between formulations 1 and 2 of the noodles. The hardness of the formulation 1 noodles was $37.61 \pm 0.41$, while substitution with lemuni leaf powder increased the hardness to $45.02 \pm 0.46$. The adhesiveness was $367.13 \pm 31.93$ for the formulation 1 noodles and $642.62 \pm 79.36$ for the formulation 2 noodles. Li (2003) revealed that when the water absorption level increases, the textural characteristics of the noodles will decrease significantly. It was noted earlier that the noodles of formulation 1 may have a higher water absorption ability compared to those of formulation 2, thus affecting the characteristic of the texture.

\section{Conclusion}

Since lemuni leaves powder has successfully incorporated in the noodles, a further study on the antioxidant activities that present in the noodles should be determined. The antioxidant activities that present in the noodles can be an extra plus point to promote lemuni noodles as a healthy, antioxidant-fortified noodle. Additionally, a study on the storage properties and packaging materials can be carried out to determine the suitability of lemuni noodles storage. Since lemuni noodles contain phenolic compounds, it was important to determine the best way to keep the fresh noodles to retain its nutritive value.

\section{Acknowledgments}

Short term grant of Universiti Sains Malaysia (304/ 
PTEKIND/6312124) contributed to the funding of this research.

\section{References}

AOAC. (2000). Official Methods of Analysis. 17th ed. Washington DC: Association of Analytical Chemists.

Brindha, S., Thamaraiselvi, T., Maragathavalli, S., Annadurai, B. and Gangwar, S.K. (2012). Studies on the chemical and medicinal value of Vitex negundo Linn. International Journal of Advanced Biological Research, 2(2), 298-301.

Dai, J. and Mumper, R.J. (2010). Plant phenolics: extraction, analysis and their antioxidant and anticancer properties. Molecules, 15, 7313-7352.

$\mathrm{Fu}$, B.X. (2008). Asian noodles: history, classification, raw materials and processing. Food Research International, 41, 888-902.

Ghaffar, S., Abdulamir, A.S., Fatimah, A.B., Roselina, K. and Nazamid, S. (2009). Microbial growth, sensory characteristics and $\mathrm{pH}$ as potential spoilage indicators of Chinese yellow wet noodles from commercial processing plants. American Journal of Applied Sciences, 6(6), 1059-1066.

Gibson, G.R. and Williams, C.M. (2000). Functional Foods, Concept to Products. Boca Raton: Woodhead Publishing Limited.

Hou, G.G., Otsubo, S., Okusu. H. and Shen, L. (2010). Noodle Processing Technology in Asian Noodles Science. In Hou, G.G. and Hoboken, N.J. (Eds.) Technology and Processing, p. 99-140. UK: John Wiley and Sons, Inc.

Kim, M.Y., Freund, W. and Popper, L. (2006). Noodles and Pasta. In Popper, L., Schäfer, W. and Freund, W. (Eds.). Future of Flour: A Compendium of Flour, p. 330-353. Germany: Verlag Agrimedia

Kong, S., Kim, D.J., Oh, S.K., Choi, I.S., Jeong, H.S. and Lee, J. (2012). Black rice bran as an Ingredient in noodles: chemical and functional evaluation Journal of Food Science, 77(3), C303-307.

Kumar, M., Dandapat, S., Kumar, A. and Sinha, M.P. (2013). Determination of nutritive value and mineral elements of five-leaf chaste trees (Vitex negundo Linn) and malabar nut (Adhatoda vasica Nees). Academic Journal of Plant Sciences, 6(3), 103-108.

Li, M., Zhang, J.H., Zhu, K.X., Peng, W., Zhang, S.K., Wang, B., Zhu, Y.J. and Zhou, H.M. (2012). Effect of superfine green tea powder on the thermodynamic, rheological and fresh noodle making properties of wheat flour. LWT- Food Science and Technology, 46, 23-28.

Li, J.Y. (2003). Noodle Dough Rheology and Quality of Instant Fried Noodles. Montreal, Quebec, Canada: McGill University, MSc. Thesis

Rabeta, M.S. and An Nabil, Z. (2013). Total phenolic compounds and scavenging activity in Clitoria ternatea and Vitex negundo Linn. International Food Research Journal, 20(1), 495-500.

Ritthiruangdej, P., Parnbankled, S., Donchedee. S. and Wongsagonsup, R. (2011). Physical, chemical, textural and sensory properties of dried wheat noodles supplemented with unripe banana flour. Kasetsart Journal: Natural Science, 45, 500-509.

Senatore, F., Napolitano, F. and Özcan, M. (2003). Chemical composition and antibacterial activity of essential oil from fruits of Vitex agnuscastus L. (Verbaneceae) growing in Turkey. Journal of Essential Oil Bearing Plants, 6(3), 185 - 19.

Vishal, R.T. (2005). Medicinal uses and biological activities of Vitex negundo. Natural Product Radiance, 4(3), 162 - 165.

Vishwanathan, A.S. and Basavaraju, R. (2010). A Review on Vitex negundo Linn. - A Medicinally Important Plant. European Journal of Biological Sciences, 3(1), 30- 42 .

Yu, J. M., Xu, D.G., Hang L., Bian, N. X. and Min, W. (2013). Cooking, textural, sensorial and antioxidant properties of common and tartary buckwheat noodles. Food Science Biotechnology, 22(1), 153 159. 